\title{
Causes of Restocking Delays in Absence of Real Time Inventory Tracking of Airtel Airtime
}

\author{
Eddie Musana1 , Annabella H. Basaza-Ejiri² \\ ${ }^{1}$ Department of Computer, Faculty of Science and Education, Busitema University, Tororo, Uganda \\ ${ }^{2}$ College of Computing and Information Systems (CoCIS), Makerere University, Kampala, Uganda \\ Email: eddiemusana@gmail.com, annabella.habinka@cit.ac.ug
}

How to cite this paper: Musana, E. and Basaza-Ejiri, A.H. (2020) Causes of Restocking Delays in Absence of Real Time Inventory Tracking of Airtel Airtime. Journal of Data Analysis and Information Processing, 8, 320-340.

https://doi.org/10.4236/jdaip.2020.84019

Received: September 16, 2020

Accepted: November 14, 2020

Published: November 17, 2020

Copyright () 2020 by author(s) and Scientific Research Publishing Inc. This work is licensed under the Creative Commons Attribution International License (CC BY 4.0).

http://creativecommons.org/licenses/by/4.0/ (c) (i) Open Access

\section{Abstract}

The purpose of this research was to ascertain causes of Restocking Delays in a Distributor Company of Airtel Airtime $(A A)$ that give justification for benefits of using Real Time Inventory Tracking (R.T.I.T) in an attempt to mitigate Restocking Delays. From a study out at the Private Marketing and Trading Services (PMTS) an Authorized Distributor of Airtel Products undertaken in 2017 evidenced by Airtime scratch card and Electronic, E-Recharge Airtime among other forms to encourage R.T.I.T among other products in Telecom Companies and other Business Enterprises. The research comprises of the following areas among which included a detailed focus on a Qualitative and Quantitative approach in obtaining different categories of Restocking Delays in form of Themes and Sub Themes encountered in the Distribution Supply Chain ( $S C$ ) of $A A$ that is contained in this paper. This research continues to capture an in-depth explanation of the Managerial and Operational causes of restocking delays in respect to $A A$. Similarly, fast consumer products and services other than $A A$ require a solution to Restocking Delays through implementation of Real Time Inventory Tracking Model (R.T.I.T.M) of $A A$ among Distributor Companies (DCs). This paper also elaborated on Literature, Methodology and Findings obtained from the study. The results were obtained from regression analysis by using the Statistical Package for Social Sciences (SPSS) that showed a higher significance of Stock Turnover Period and Airtime Denomination as a contributor to Restocking Delays whereas Messages from Airtel Head office to the Distributor had a non-significant contribution to restocking Delays as in Figure 9. The research recommends a Model for R.T.I.T in Telecom Distribution SC of $A A$ and Omnichannel Inventory Management (OIM) as a significant contributor to timely reliable inventory restocking and promotes higher sales among DCs and retailers through minimized Restocking Delays. It shows that the forces of Demand and Supply change over time with different tastes and preferences 
of customers. The imbalance in $A A$ stock levels changes at given times due to unforeseen forces of consumer demand experienced by $D C s$, explained by the "Bullwhip Effect" due to information distortion in the Supply Chain $(S C)$.

\section{Keywords}

Bullwhip Effect, Distribution Supply Chain, Managerial Causes, Omnichannel Inventory Management, Operational Causes, Restocking Delays and Telecom Company

\section{Introduction}

The research background gives an overview of Distribution technologies; the industry is highly computerized and there was need to identify the gaps in the Real-Time aspect that exist within the $A A$ distribution process [1]. For example there is a real-time gap between the Distributors to the end customer. There is need for the retailers and other medium whole-sellers to collaborate with their Distributors to upgrade their purchasing and Supply Management Function from clear role to an integral part that modernizes the phenomenon in extension of Supply Chain Management (SCM) and information technology infrastructure plays a crucial role in improving $S C M$ capability and in Supply Chain $(S C)$ strategy, an increase in the use of Information Communication Technologies (ICT) has a positive influence on vendor relationship management and Customer Relationship Management (CRM) [2]. From the research on "information distortion in a supply chain: The bullwhip effect" it considers a series of companies in an $S C$ of which orders are made from the immediate upstream member and in that study, inbound orders from a downstream member serve as a valuable input information to the upstream production and inventory decisions. This reveals that the information from "orders" can misguide upstream members in their inventory and production decisions. As a case in point, the variance of orders may be larger than that of sales; this distortion tends to increase as one moves upstream and the term given to this phenomenon is "bullwhip effect" [3].

The situation of other researchers includes that, the causes of delays in inventory restocking are grouped into two categories that comprise of Operational and Behavioural causes of delays: the first category comprises of Operational causes of the problem that are due to errors in demand forecasting, order batching, gaming due to perceived or real shortage and discount fluctuations. Such causes of delays in inventory restocking have been documented in practice and the techniques to eliminate the delay are an important part of the tool kit in supply chain design [4]. The Behavioural causes of delays include experimental studies: explanation emphasizes the bounded rationality/reasonableness of decision makers in failing to adequately account for feedback effects and time; people do not adequately account for the time delays, nonlinearities and feed- 
backs in the system. Thereby the distributor experiences a situation where orders due to demand may exceed the stock that could currently be available [3].

The problem intended to be solved arises as follows: Distributor Companies $(D C s)$ tend to place orders depending on the gap between the inventory target level and the current inventory levels including on hand stock. As a result, insufficient weight is given to the supply line of unfilled orders that is to say, the stock of orders placed but not yet received [4]. This research, majorly looked at the Telecom $D C$, of which the industry is highly computerized and there was need to identify the gaps in the real-time aspect that exist within the $A A$ distribution process [1]. For example there is a real-time gap between the distributors to the end consumer. There are majorly four causes of Bullwhip Effect which include: demand signal processing, the rational game, order batching, and price variance, usually under certain conditions like when past demands are not used for forecasting (for example when demand is static or stationary), resupply is infinite with a fixed lead time.

Therefore, appropriate use ICT in bridging the real time gap at the Distributor Company (DC) whereby automatic update stock inventory levels can be instantly without taking a lot of time to manually ascertain how much Airtime stock is needed to be restocked at the Distributor Company, thus contributing to a positive influence on vendor relationship management and Customer Relationship Management (CRM) [2].

"Shortage of Airtime" is a term commonly used by Airtel Distributor when the demand of certain denominations of airtime exceeds the available stock at the $D C$ premises and perhaps the researcher seeks to use the word "Bullwhip Effect" since the research that was carried out in "information distortion in a supply chain: The Bullwhip Effect" [3] seems to be related to the study that the researcher had undertaken. So when the forces of demand and supply change over time with the different tastes and preferences of customers, the retailers and stockiest (traders who buy $A A$ in bulk) tend to purchase or order for Airtel Airtime $(A A)$ which is mostly consumed by the final customers.

Therefore when the levels of stock run low or rather become insufficient at the Airtel Authorized Distributor, the distributor has to make an order for more $A A$ denominations at Airtel Uganda, which is the Telecom Company itself. The process of replacing the stock of $A A$ by the Distributor after it has been sold is commonly referred to as "Restocking". Order costs and the purchase cost of the product are not stationary over time.

\section{Problem}

On certain occurrences, one may walk to an Airtime vendor to purchase a specific Airtime denomination or an amount worth of E-Recharge Airtime and may not be available, perhaps due to unforeseen increase in the forces of demand. As a result, the Direct Sales Representatives (DSRS) who supply the retailers/vendors with either Airtime Scratch Card or E-Recharge Airtime may experience the same scenario when the Airtime amounts ordered by each $D S R$ at 
the Distributor Company $(D C)$ may be insufficiently available at the $D C$ thus resulting into a problem of the inability to automatically show/determine the levels of stock available at any given time contributes to delay in restocking at the $D C$ of Airtel Airtime leading to loses. Similar examples include Hershey's 1999 meltdown when it failed to deliver $\$ 100$ million Kisses and Jolly Ranchers to stores in time for Halloween because of a failed supply chain system [5], JPMorgan Chase lost $\$ 6$ billion in 2012 due to errors made on its Microsoft Excel spreadsheet. Therefore these examples prove that when the core business processes are ignored that comprises a dedicated Real Time Inventory Tracking System, it increases the risk of destroying business. Therefore lack of transaction and inventory visibility continues to be a significant challenge.

\section{Literature}

\subsection{Why Inventory Uncertainties Is an Important Problem}

It is a laborious task of poring over inventory, tracking goods, recording sales, restocking shelves in a timely manner and predicting future demands have never been an easy activity for those running businesses with the growing day to day challenges, as a result business end up running to the ground [5].

For the literature on the purposive sampling technique used and the significance of an R.T.I.T.M presence in the Distribution Supply Chain of Airtel Airtime, detailed information is captured in the first journal [6].

Below are some of the companies that lost control of their inventory and almost ruined their businesses:

Target's out-of-stock disaster in 2015 when pink Barbie SUVs piled high in target's distribution centers and killed the discount retailer's big entry into the Canadian market, even the barcodes on the Barbie toy cars did not match the numbers in the computer system. Target grew too fast, too quickly without taking proper precautions and mismatched inventory left shelves empty, customers frustrated and the third largest store in the United States lost more than $\$ 2$ billion.

Walmart's missing goods have struggled to keep shelves stocked with merchandise for years, and in 2011, the retailer hired firms Acosta Incorporation and Retail Insights to literally walk down its lanes to track items. However in 2013 Walmart was back to the red zone. Thus misplaced goods resulted in the company's $\$ 3$ billion loss as inventory continued to grow faster than sales.

Kmart's lack in foresight, in the mid-to-late 1990s when Kmart and Walmart were having price wars, Walmart decided to implement a supply chain system known as "just-in-time" inventory that allowed shelves to be restocked efficiently. However Kmart did not take any step to adopt a modern supply chain management system, the stock price for Kmart dropped 63\% and Kmart in 2002 filed for bankruptcy, closed hundreds of stores and merged with Sears Roebuck in 2005. Whereas between June 1998 and June 2000, the stock prices for Walmart rose by $82 \%$ [5]. 
The most recognized athletic brand, Nike's long tough battle with supply chains. Have lots of goods to manage and lost a lot from its inability to keep inventory under control over the years. Inventory uncertainty is an important problem because after losing around $\$ 100$ million in sales due to issues with tracking goods, In the early 2000s, Nike Company adopted an updated inventory management software to predict items that would sell best and prepare the company to meet demands but bugs and data errors resulted in incorrect forecast and led to loss of more millions [5].

Inability to deliver in specific seasons (Christmas): in December 2011 a company called Best Buy, BestBuy.com failed to redeem the online customer orders due to overwhelming demand and poor inventory management led to stock outs, thus it could not delay shipment and lost lots of its customers to Amazon after the 2011 incident [5].

The existence of imbalanced supply and chain demand, Ralph Lauren's iconic clothing always looks so clean, it is unbelievable that the American sports wear had confused inventory system, profits dropped by 50 percent in 2014, consequently the company is now worth half of the $\$ 16$ billion is was worth in 2012 because it could not get inventory under control and in an attempt to solve the problem, there was need to focus on the brand's bestselling labels, cutting multiple layers of management and closing 50 underperforming stores [5].

There is an observation on Local-based Mobile Promotions (LMP) that drives non-impulsive, delayed sales because it may engender need recognition, future consumption decision-making and planned purchase behavior. The theory of real-time marketing is reconciled with planned behavior because of the significance in location and time proximity and impacts on contemporary sales but not on delayed sales [7]. Therefore there is need to monitor sales performed during $L M P$ as airtime sales may be significantly higher than the normal supply.

Considering firms that independently manage inventories and ordering quantity, these incur inventory and shortage costs in other words experience random demands for such quantities faced by firms which like distribution firms, enable ascertainment of inventory costs faced the firm including the market price of buying the product. An optional ordering cost minimization for each of the firms yields an optional quantile risk that each distribution firm can use in determining the order quantity if were to self-manage inventories [8].

Much as a new multi-stage risk prevention strategy bases on Time Stochastic Dominance (TSD) along a given horizon considers a mixture of two risk prevention/avoidance measures based on first and second order stochastic dominance constraints induced by mixed integer-linear recourse, respectively. It is therefore unrealistic to solve the inventory problem up to optimality by plain use of Management Incentive Plan (MIP) as the dimensions of medium-sized problems augmented by the new variables and constraints are required by this new risk measure. A decomposition algorithm of some type is suggested [9], which is an extension of a Branch and Fix Coordination algorithm called Branch and Fix Coordination-Time Stochastic Dominance (BFC-TSD). Broad computational 
experience is presented by comparing the risk neutral approach and the tested risk avoidance strategies.

In the aspect of this paper, the returns by Direct Sales Representatives can be sold in the subsequent days bearing in mind that products have expiry dates and those that do not perish. Therefore stochastic stock management can be focused upon that are essential [10] and in addition to established frameworks for some future works, R.T.I.T.M can be very efficient to minimize delays in computing sales and returns because the top inventory challenges faced in the Telecom/Communications is the challenge of a typical retail foot print that needs visibility to their stores so they provide an Omni-channel experience for the sales of phones and other accessories among other products just like retailers [11].

Inventory systems that scale up or down automatically without additional workload to the Information Technology department, are required by Omnichannel commerce that revolves around customer and creates a single customer experience across the brand by unifying sales and marketing that accounts for the spillover between channels.

It is emphasized that legacy systems were not built to scale to current customers and Omnichannel Inventory Management (OIM) revels that $72 \%$ of retailers agree that $O I M$ is a major factor in meeting their company's financial goals [12] [13] and nearly half of the retailers $49 \%$ reported that they have a "few advanced systems and processes" in place to achieve smooth, accurate and cost-effective Omnichannel Inventory Management [13].

\subsection{Preventable Causes of Stock Outs}

Inaccurate data arises when dealing with inventory due to misplaced products and returns, where merchants may not know the exact stock of products available and may end up re-ordering for the wrong products or quantities. This cause of inaccurate data can be preventable through the use of modern inventory system as the first step avoiding discrepancies is to implement an electronic (ideally cloud-based) inventory system. This preventable cause suggests that keeping track of products using a pen and paper is not only time consuming but can also lead to mistakes. Therefore, it's best to use a point-of-sales or inventory system that automatically modifies inventory levels as you ring up sales to avoid worries in manually updating the database, such solutions are also beneficial if you have several locations because they allow you to manage multiple stores from one place. Stay organized and vigilant to prevent delivery of wrong quantities of products. Conduct regular stock counts to have accurate numbers by tracking and updating stock, as modern inventory systems can do a great job at keeping and updating the stock levels in check, there is more need to handle the amount of physical inventory available [14].

Failure to re-order in a timely manner as a cause of restocking delay that can be preventable by closely identifying and following the Out of Stock (OOS) patterns of the stock inventory. A study by Proctor and Gamble, P\&G found that $O O S$ "tend to form patterns such as day of the week", the distributor can find 
them by regularly auditing their inventory and taking note of the days and times of the week when they usually experience stock outs [14].

\subsection{Benefits of Encountering Delays Using R.T.I.T}

The benefits to the distributor include improvement in Supply Chain $(S C)$ speed and reliability, identifying and minimizing any forms of deviation within $S C$ process, reduce resource consumption amidst financial constraints and then strengthen trust and political issues in the $S C[1]$.

The benefits of the consumers are that R.T.I.T reduces the delays "Bullwhip Effect" since factors such as rationing, shortage and lead time are most effective in reducing the Bullwhip Effect [15] of Airtel airtime products in the market and also increase on the consumption of various Airtel airtime products.

\section{Methodology}

The methodology involved obtaining permission and consent from the Distributor Company to collect Data, observations were made, Interviews were conducted and Questionnaires issued to the respondents. Collected data was both Qualitative and Quantitative analyzed using Regression Analysis Technique. As emphasized in the recent paper of "Real Time Inventory Tracking Model in the Distribution Supply Chain of Airtel Airtime" [6], the sample size was small and Purposive Sampling was used to select the sample size.

The dataset was analyzed using various statistics methods; the descriptive statistics are used to summarize large datasets through limited number of statistical indicators, for this study frequency distribution is conducted and presented in sub sections and analyzed data is therefore presented on the themes of Daily, Weekly, Monthly, More than Two months and Within two weeks for the stock turn over period. Also the denominations 500/=, 1000/=, 2000/=, 5000/=, $10,000 /=$ and $20,000 /=$ where this information is captured in the findings. Descriptive statistics included use of frequency distribution to indicate how the scores of individual respondents are distributed for each of the variables and each variable is examined at a time [16]. The variable name and description are shown by a frequency distribution and cumulative percentage for each value associated with a variable [17].

The questionnaire drew responses on factors that investigated the causes of delayed restocking to justify the need for Real Time Inventory Tracking Model (R.T.I.T.M) in the business $S C$ of $A A$ for an Authorized Distributor. The collected data was quantified, coded and entered into Statistical Package for Social Sciences (SPSS). Analysis was then presented in themes that included: Messages from Head office that distributor is running out of airtime, the "Bullwhip Effect" period, stock turnover of mostly restocked airtime, stock turnover of NOT regularly restocked Airtime and Limitation size of storage space.

The Design of Investigated Causes for Different Stock Turn Over Periods

To investigate the causes of Restocking delays, Figure 1 was used to formulate 
the hypothesis. Where $\mathrm{H}_{1}, \mathrm{H}_{2}$ and $\mathrm{H}_{3}$ are the different Hypothesizes that have been explained in the subsequent paragraph as follows to determine which ones have a significant or non-significant contribution to delays encountered during Restocking of $A A$ :

According to the design above, a delay in restocking of $A A$ at the $D C$ causes Bullwhip Effect Period [3] is experienced when the customer demand is higher than company sales and some factors considered included Stock Turnover Periods, the Airtime Denominations of Mostly Restocked $A A$ product including Messages from Airtel that the Distributor is running out of airtime has an influence on Bullwhip Effect Period that can be solved by implementation of a Real Time Inventory Tracking Model (R.T.I.T.M) in Telecom Distribution for the Distributor Company that aims at minimizing the occurrence of Bullwhip Effect and its effects.

The relationship/hypothesis proposed included the following:

$\mathrm{H}_{1}$ : There is a significant relationship between Airtel Denomination of the Mostly Restocked Airtel Airtime $(A A)$ and Bullwhip Effect that can be minimized by Real Time Inventory Tracking Model.

$\mathrm{H}_{2}$ : There is a significant relationship between Stock Turnover Period (STP) and Bullwhip Effect that can be minimized by R.T.I.T.M.

$\mathrm{H}_{3}$ : There is a significant relationship between Messages from Airtel and Bullwhip Effect that can be minimized by R.T.I.T.M.

\section{Findings}

Respondents' views were obtained to ascertain the interval of delays in selling similar denominations of airtime in the absence of Real Time Inventory Tracking Model that was aimed at minimizing the time within the "Bullwhip Effect" due to the Delays in restocking of airtel airtime. Figure 2 shows the time taken in the "Bullwhip Effect" period or delay in restocking period. The calculations were further supported by the Regression Analysis that was performed to establish the relationships among variables.

Multiple regression analysis method was used for the dependent variable and three independent variables to be analyzed. Regression analysis statistical technique was used because it is a predictive technique that allowed establishment of

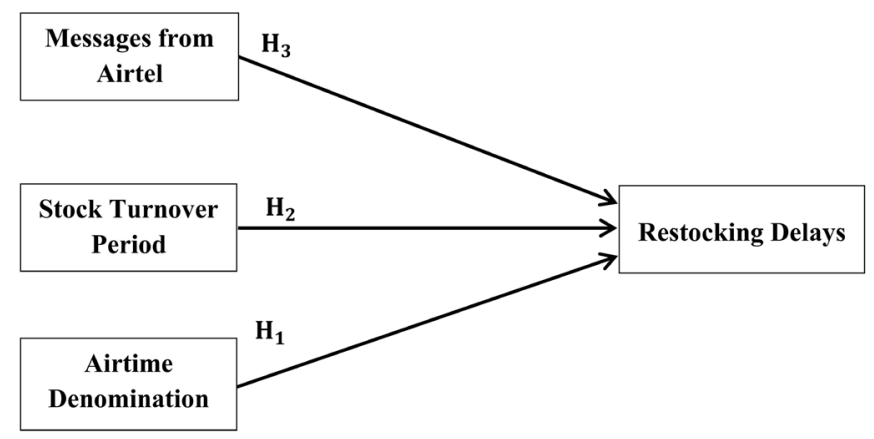

Figure 1. The design of investigated causes of restocking delays. 
relationships between the independent/predictor variables and the dependent/criterion. That is to say, knowing the independent variable Stock Turnover Periods enables to predict the dependent variable (Bullwhip Effect Periods). In general, the format the multiple regressions take is as follows:

$$
Y=a+b_{1} * x_{1}+b_{2} * x_{2}+\ldots+b_{n} * x_{n}+u
$$

\section{where}

$Y=$ Dependent variable

$X_{1} \ldots X_{n}=$ Independent variables

$a=$ Constant

$b=\mathrm{B}$ coefficient

$n=$ Number of independent variables

$u=$ Error

Therefore this study:

$Y=$ Bullwhip Effect Period

$X_{1} \ldots X_{n}=$ Independent variables (Messages from Airtel "that distributor is running out of Airtel airtime", Stock Turnover Periods, Airtime Denominations "that are mostly re-stocked products").

$a=$ constant/intercept (that gives the value of $Y$ at a point where the regression line crosses the $Y$ axis at the point $X=0$ ).

$b=\mathrm{B}$ coefficient/Regression coefficient/slope of the regression line represent the independent contributions of each independent variable from an illustration in Figure 9 that takes on the following form of general equation:

$$
Y=a+b_{1} * x_{1}+b_{2} * x_{2}+\ldots+b_{n} * x_{n}+u
$$

The Bullwhip Effect Period $=3.000+1.307 \mathrm{E}^{-15}\left(X_{1}\right)+1.000\left(X_{2}\right)+1.000\left(X_{3}\right)+u$

The values of the independent variables $X_{1}, X_{2}, X_{3}$ corresponding to Messages from Airtel, Stock Turnover Periods and Airtime Denominations of "mostly restocked airtime products" respectively can be assumed in so as to predict the expected value of $Y$ (Bullwhip Effect Period "that has to be minimized"), which is the dependent variable.

\subsection{The "Bullwhip Effect" Period at Airtel Authorized Distributor}

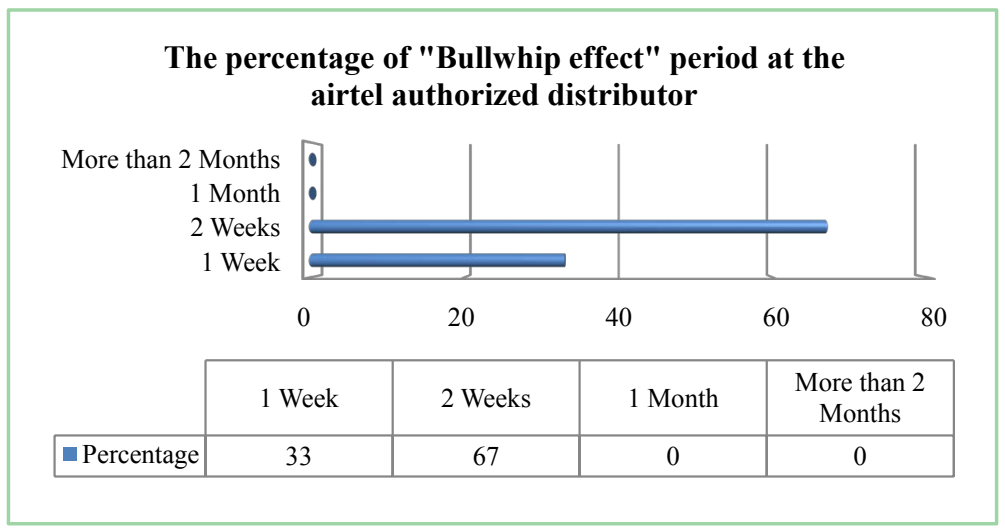

Figure 2. The percentage of "Bullwhip Effect" at the Distributor Company. 


\subsection{Messages from Head Office, Distributor Running out of Airtime}

The messages are sent from Airtel Head Office to the distributor when they are running out of certain denominations of Airtel Airtime $(A A)$; this takes place when the customer finally loads the $A A$. This takes place when the customer finally loads the $A A$. However for restocking to be made, the Authorized Airtel Distributor does not have to wait for the end consumer to finally load the airtime. Therefore the Model for R.T.I.T is to enable the Authorized Distributor to automatically replace the sold airtime stock without necessarily waiting for the Message from Airtel Head Office. Figure 3 shows the percentage for period when Airtel Head office sent messages that the Distributor is running out of airtime.

\subsection{Stock Turnover of Mostly Restocked Airtel Airtime}

Figure 4 illustrates the different intervals in periods for the Stock Turnover period of Mostly or frequently restocked $A A$. The Airtel Airtime stock turnover of the mostly restocked airtime is at $67 \%$ weekly, followed by $25 \%$ within two weeks and the least airtime restocking period is at $8 \%$ daily. This implies that the restocking intervals take a slightly shorter time which is better and there is no restocking made at Monthly which is $0 \%$ or More than two months at $0 \%$ for the Mostly Restocked Airtel Airtime.

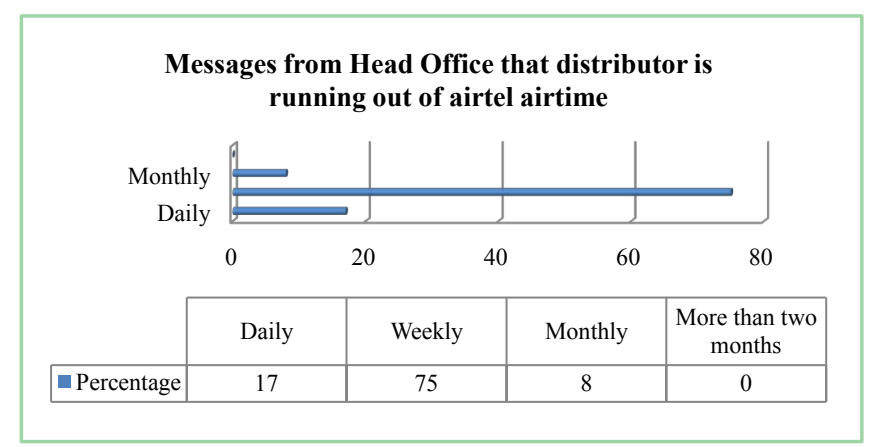

Figure 3. Messages from head office that distributor is running out of Airtel Airtime.

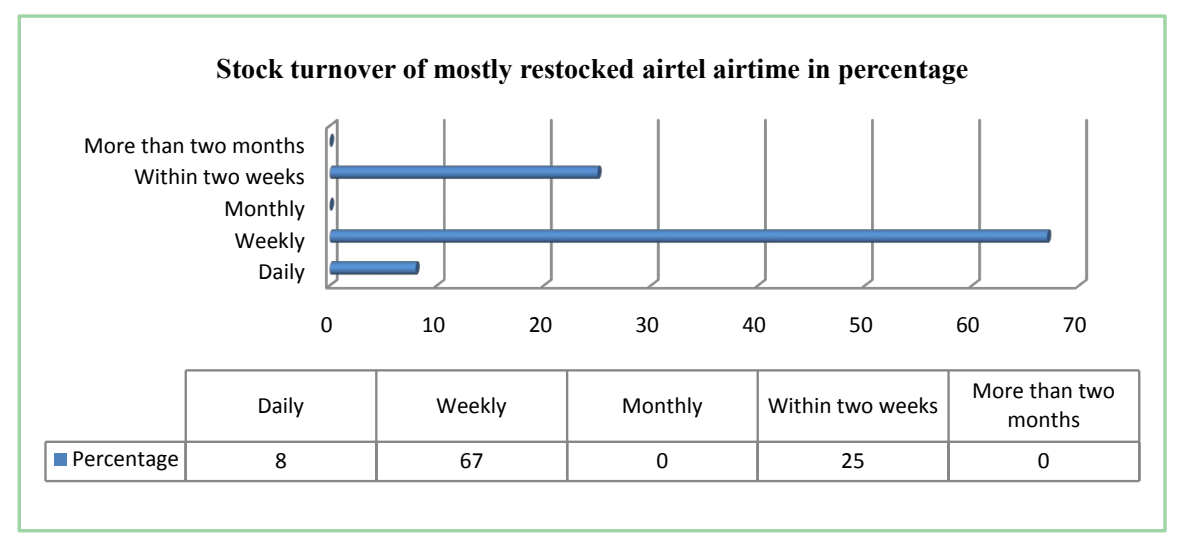

Figure 4. Stock turnover of mostly restocked Airtel Airtime. 


\subsection{Stock Turnover of Not Regularly Restocked Airtime}

Figure 5 indicates that Stock Turnover of NOT regularly restocked Airtime is at $100 \%$ monthly. Perhaps the consumption rate of Airtel Airtime is relatively low and it takes slightly a longer time period to sell the airtime stock and hence replace the sold stock as compared to the Airtel Airtime which is mostly restocked in Figure 4.

\subsection{Limitation Size of Storage Space}

From Figure 6, was used in this research to ascertain the existence and size of storage space available at the Distributor Company so as to get a basis on the possibility of advancing to real time inventory tracking of airtime products. The storage space at Airtel Authorized Distributor from the respondents indicates that $50 \%$ Not enough (Limited Storage Space), $42 \%$ Very Small storage space, $8 \%$ say there was None. Implying that there was no Unlimited Storage Space and no Medium storage space since the response for this category was at $0 \%$.

The statistics indicate that the storage space is sufficient enough for Distributor Company and there is need for Unlimited Storage Space to track the inventory on Real Time over a long period of time throughout the Distributor's existence.

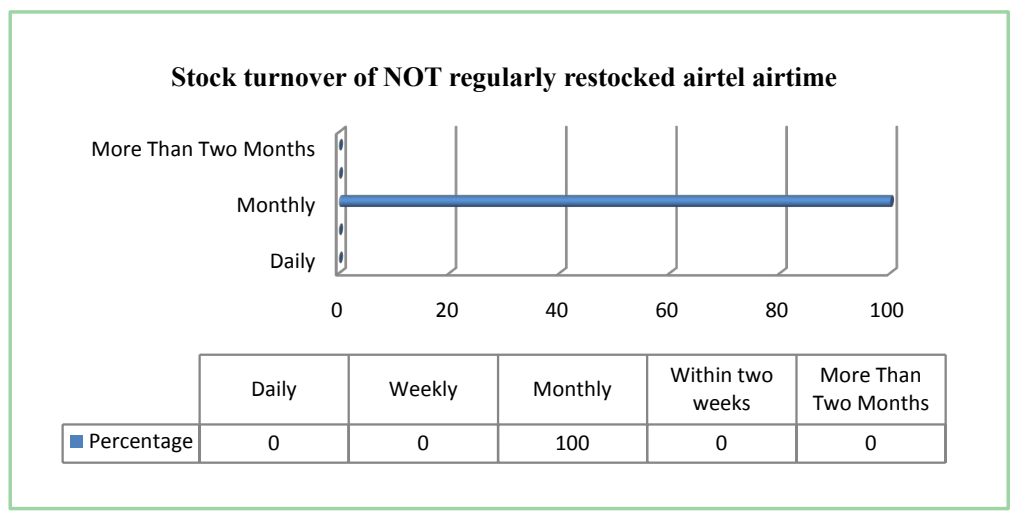

Figure 5. Stock turnover of NOT regularly restocked Airtel Airtime.

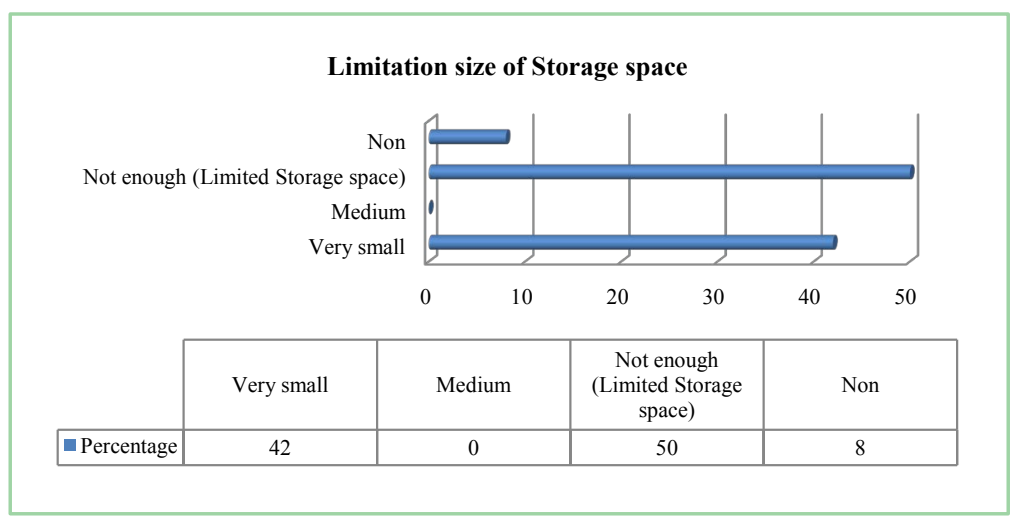

Figure 6. The limitation size of storage space at the Authorized Distributor. 


\subsection{Direction of Relationship and Level of Significance}

Regression analysis coefficients for the predictor variables (independent variables) Messages from Airtel, Stock Turnover Periods and Airtime Denominations were computed to determine the nature of relationship to establish how much change the independent variables associates with that of the dependent variable of Bullwhip Effect Period thus determining the level of significance in each variable, the multiple regression analysis Table presented the results as below.

The explanation in Table 1 is as follows: The unstandardized coefficients were obtained from regression of original (unstandardized) variables whereas the Standardized coefficients or beta coefficients are estimates that resulted from analysis carried out on independent variables that have been standardized so that their variances are 1 . The results in Table 1 are a display from SPSS, the "B" coefficients therefore help to determine the direction of relationship between variables. The positive " $\mathrm{B}$ " coefficient implies a positive relationship of the variables with the dependent variable, a negative " $B$ " coefficient represents a negative relationship but if the " $B$ " coefficient is zero then there is no relationship between the variables.

Sig. (P value) represents the level of significance between the independent variables and the dependent variables. A higher $\mathrm{P}$ value shows a less significant relationship between the variables whereas a lower $\mathrm{P}$ value shows that the observed relationship between variables is a reliable relationship between the respective variables.

\section{Results}

Results showed the existence of a linear relationship between messages and mostly restocked Airtel Airtime whereas there was NO linear relationship between "Bullwhip Effect" and NOT Mostly restocked airtime. In addition to the above, the calculation formulae from also obtained from the regression analysis as shown in the table below. Therefore the first relationship is obtained by extracting a graph from the data that was collected used to represent the bar graphs in Figure 3 and Figure 4. Hence by using Microsoft Excel data analysis package, the regression graph in Figure 7 was obtained. Similarly in the second relation, the regression graph in Figure 8 was obtained by extracting Figure 8 by plotting a regression from the same data that was used to extract the graphs in Figure 2 and Figure 5, however it turned out not to display any relationship between "Bullwhip Effect period" and NOT Mostly restocked airtime.

From the strength of relationship between the independent variables and the dependent variables was determined by Regression analysis. Results showing strength of relationships are presented in the model summary in Table 2.

The table above presents the model summary, the predictors of Real Time Inventory tracking in the model. The multiple correlation coefficients $R$ which represents the square root of $R$ Square show how strongly the independent vari- 
able relates with the dependent variable. $R$ has to vary from 0 to 1 , in the above, $R=1.000$ that implies that the relationship a very strong relationship between the independent variables and the dependent variable. The $R$ square values vary from 0 to 1; thus 0 indicates NO relationship and 1 indicates a perfect relationship. Hence the closer the $R$ square value to 1.000 , the better the model implying that it's easier to better predict one term from another whereas the closer the $R$ square value to 0 indicates, the worse the model implying that it's harder to know one term does not help to know the other at all.

Table 1. Coefficients.

\begin{tabular}{|c|c|c|c|c|c|}
\hline \multicolumn{6}{|c|}{ Coefficients $^{*}$} \\
\hline \multirow{2}{*}{ Model } & \multicolumn{3}{|c|}{ Unstandardized Coefficients Standardized Coefficients } & \multirow{2}{*}{$\mathrm{T}$} & \multirow{2}{*}{ Sig } \\
\hline & B & Std. Error & Beta & & \\
\hline 1. (Constants) & 3.000 & 0.000 & & $1.181 \mathrm{E} 8$ & 0.000 \\
\hline Message from Airtel & $1.307 \mathrm{E}-15$ & 0.000 & 0.000 & 0.000 & 1.000 \\
\hline $\begin{array}{l}\text { Stock Turnover Periods } \\
\text { (Mostly Re-stocked) }\end{array}$ & 1.000 & 0.000 & 1.000 & 7.457E7 & 0.000 \\
\hline $\begin{array}{l}\text { Airtime Denomination } \\
\text { (Mostly Re-stocked) }\end{array}$ & 1.000 & 0.000 & 1.000 & 7.457E7 & 0.000 \\
\hline
\end{tabular}

a. Dependent Variable: Bullwhip Effect Period.

Table 2. Model summary of bullwhip effect and predictors.

\begin{tabular}{ccccc}
\hline \multicolumn{5}{c}{ Model Summary } \\
\hline Model & $R$ & $R$ Square & Adjusted R Square & Std. Error of the Estimate \\
\hline 1 & $1.000^{\mathrm{a}}$ & 1.000 & 1.000 & 0.000 \\
\hline
\end{tabular}

a. Predictors: (Constant), Stock Turnover Periods-(Mostly Re-stocked), Message from Airtel, Airtime Denomination

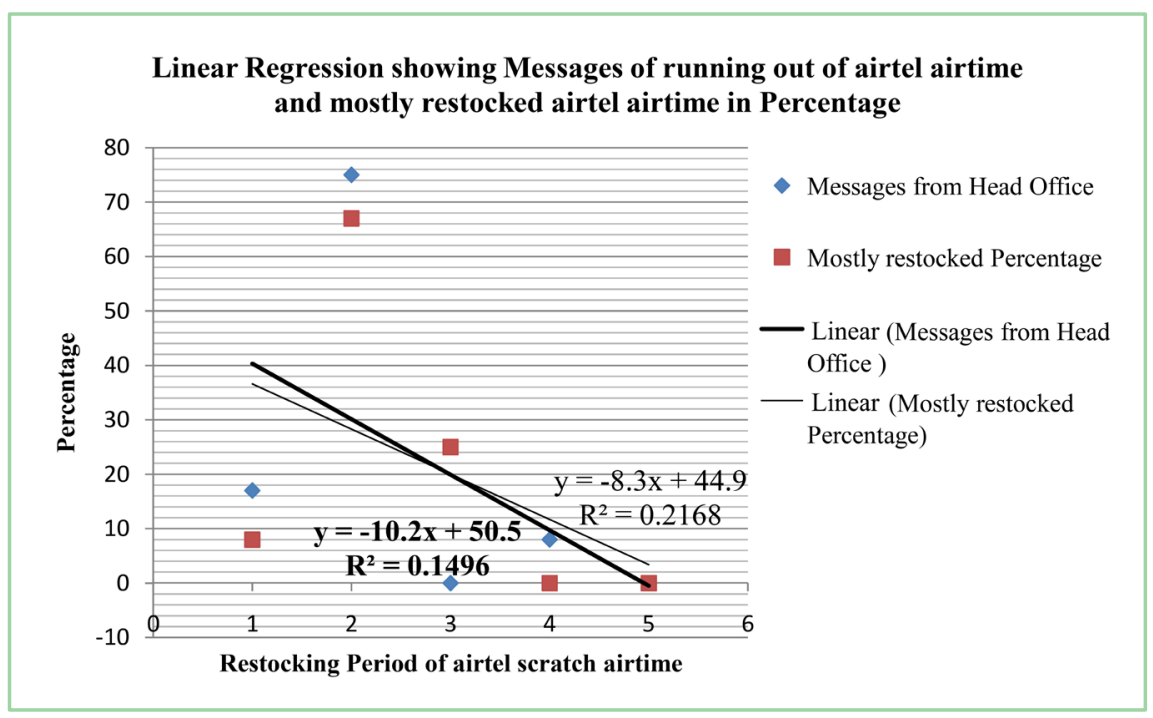

Figure 7. Linear relationship between messages and mostly restocked airtime. 


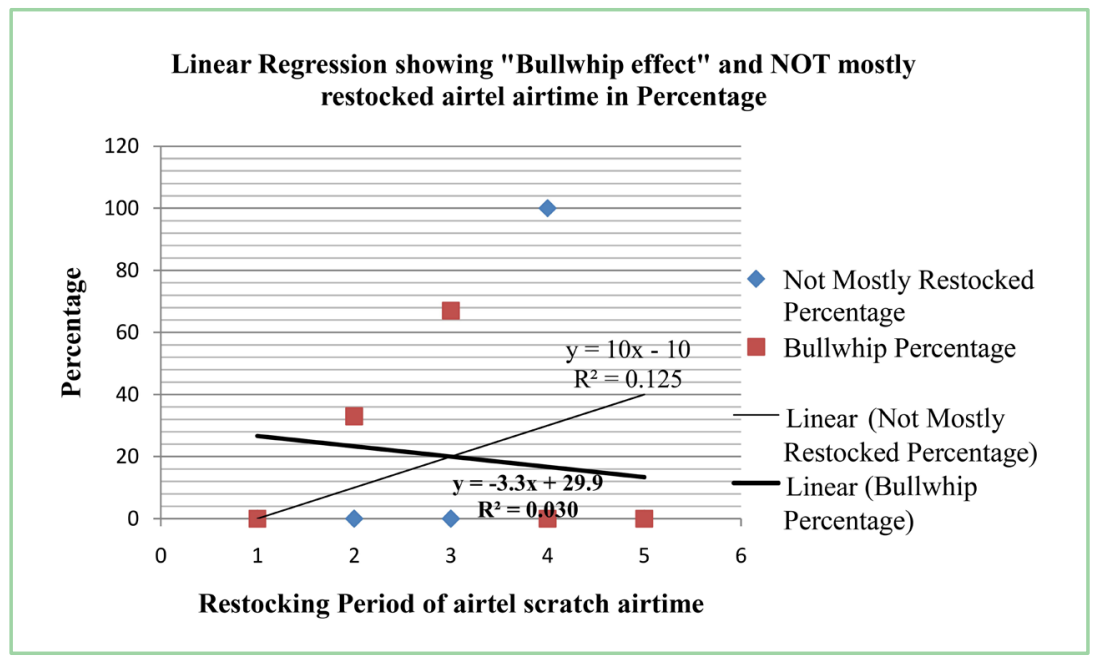

Figure 8. Relationship between "Bullwhip Effect" and NOT Mostly Restocked Airtime.

$R$ square $\left(R^{2}\right)$ for this study is 1.000 which implies that the proposed constructs (Bullwhip effect and mostly restocked Airtel airtime) explains 100\% of the variance in Real time inventory tracking. This gives the proportion of unexplained variance in the dependent variable to be $(1-R) 0.000$; part of which could be catered for by the other success factors that had not been considered in the study, it could be due to the small sample size. The addition of extraneous predictors to the model penalizes the adjustment of the $R$ square. The adjusted $R$ square to yield a more honest value to estimate $R$ square, the adjusted $R$ square for this study is $100 \%$, the standard error of estimate/standard deviation is 0.000

\subsection{Explanation of First Relationship}

\section{Linear relationship between messages and mostly restocked airtel airtime}

In Figure 7, a description is illustrated showing the existence of a linear relationship between the Messages sent to distributor that they are running out of airtime and in response to that of the various denominations of airtime. However the messages from airtel did not have a significant influence on Bullwhip effect as shown in Figure 9. The smaller diamond scattered plots represent the messages from the Head Office that indicate the distributor is running out of airtime whereas the larger squared scatted plots represented the mostly restocked Airtel Airtime.

In addition, in Figure 7 the thick line represents a line of best fit for the messages from Airtel Head Office with a linear equation of $y=-10.2 x+50.5$ and $R^{2}=0.1496$ whereas the thin line represents a line of best fit for the mostly restocked Airtel scratch or Electronic-Recharge Airtime with a linear equation of $y=-8.3 x+44.9$ and $R^{2}=0.2168$.

The lines slope downwards from right to left implying that higher sales have to be achieved in the shortest period of time following a periodical scale of Daily, Weekly, within Two Weeks, Monthly and More than Two Months; this is healthy for the distributor company unlike when the line increases upwards 
from left $(0,0)$ to the right in the form of the linear equation $y=x^{2}+0$, because it implies that the Company makes profits after a longer period which is not healthy for Business. Since the thick line of best fit for messages is above the thin line of best fit for Mostly Restocked Airtime scratch airtime within the earlier periods this implies that there are higher chances for "Bullwhip Effect" occurrence.

\subsection{Explanation of Second Relationship}

\section{Linear Regression showing "Bullwhip Effect" and NOT Mostly Restocked} Airtel Airtime (AA) in Percentage

In Figure 8, the smaller diamond scattered plots represent the NOT Mostly Restocked Airtel Scratch or E-Recharge Airtime whereas the larger squared scattered plots represent the "Bullwhip Effect" period. The thick line represents a line of best fit for the "Bullwhip Effect" with a linear equation of $y=-3.3 x+29.9$ and $R^{2}=0.0304$ whereas the thin line represents a line of best fit for the NOT Mostly restocked Airtel scratch or E-Recharge Airtime with a linear equation of $y=10 x-10$ and $R^{2}=0.125$.

The line of best fit for $A A$ which is NOT Mostly Restocked gradually increases upwards whereas the "Bullwhip Effect" gradually decreases downwards, this therefore implies there is NO relationship between the "Bullwhip Effect" with the Stock Turnover Periods of the $A A$ scratch or E-Recharge Airtime that are NOT Mostly Restocked. Study results show that out of the three (Message from Airtel, Stock Turnover Periods-(Mostly Re-stocked) and Airtime Denomination) proposed independent variables while Bullwhip Effect Period was the dependent variable. This implied that 2 out of 3 proposed variables (constructs) that is to say Stock Turnover Periods-(Mostly Restocked) B $=1.000$ and Airtime Denomination with $\mathbf{B}=1.000$ both have a very large impact in explaining variation of Bullwhip Effect "Customer demand is greater than Company sales".

The therefore implies that out of three variables, two (Stock Turnover Period with $p=0.000$ and Airtime Denomination with $p=0.000$ ) have a significant influence on Bullwhip Effect at level $\mathbf{p}<0.05$ while the remaining one variable (Messages from Airtel influence with $\mathbf{p}=1.000$ ) had a non-significant influence on Bullwhip Effect Period "when customer demand is greater than sales" having $\mathbf{B}=1.307 \mathrm{E}^{-15}$.

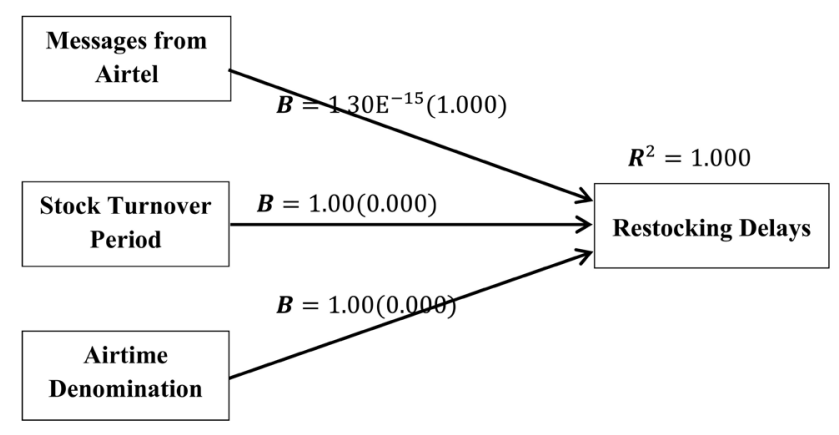

Figure 9. The regression model on causes for Restocking Delays. 


\subsection{The Regression Model on Causes of Restocking Delays}

Figure 9 shows that out of the 3 proposed constructs, 2 are Stock Turnover Periods and Airtel Denominations positively related to Restocking Delays because their respective $B$ coefficient are positive. Because both Stock Turnover Period with $B=1.000$ and Airtime Denomination with $B=1.000$, have a large impact in explaining the variation of Bullwhip Effect Period.

Out of the three variables, (Stock Turnover Period with Probability $\mathbf{p}=0.000$ and Airtime Denomination with $\mathrm{p}=0.000$ ), have a significant influence on Bullwhip Effect Period at the probability level of $\mathbf{p}<0.05$ while the remaining one variable (Messages from Airtel with $p=1.000$ ), have a non-significant influence on Bullwhip Effect Period with $\mathbf{p}=1.30 \mathrm{E}^{-15}$. Figure 9 illustrates the regression model. The results imply that for a Positive change in Stock Turnover Period leads to 1.000 in positive change of a Reduced Restocking Delays and a positive change in Airtel Denomination leads to a 1.000 in positive change of a Reduced Restocking Delays and a positive change in Airtime Denomination leads to a 1.000 in positive change in Reduced Restocking Delays. Root $\boldsymbol{R}$ square $\left(R^{2}\right)$ for this study was 1.000 which implies that the proposed constructs (Stock Turnover Period and Airtime Denomination) explain a $100 \%$ of variance in Reduced Restocking Delays.

In other words, the overall contribution of the independent variables that accounts for the variations in the dependent variables is 1.000 that suggests a $100 \%$ of Reducing Restocking Delays is explained by the independent variables. The proportion of unexplained variance in the dependent variables is therefore (1 R) 0.000 , part of which could be catered for by the other success factors that have not been included in the model.

\subsection{The Qualitative Results}

The themes were obtained from collected data on causes of Restocking Delay of Airtel Airtime at the Distributor Company that resulted from the semi-structured questions in the questionnaire that gave the respondents liberty to express their opinion from a total of 12 respondents where $\mathrm{R}$ stands for Respondents at ATLAS.ti 5.2 a qualitative data analysis tool was used to analyze the collected qualitative data.

The semi-structured questions were designed based on construct of operational and managerial causes of delay that lead to supply chain instability, this enabled respondents to give their views.

\subsection{Themes of Restocking Delays}

Figure 10 categorizes the different causes of restocking delays in form of themes that included the Operational causes and Managerial causes of Restocking delays.

\subsection{Operational Causes of Delay}

Operational delays occur due to functional difficulties that cause delays and lead 
to Supply Chain uncertainties.

Discount fluctuations: Low discounts given by Airtel Uganda to Distributors delays decision making towards restocking of airtel airtime as quoted below.

"We are delayed by discount fluctuations that are characterized by low discount and commission structured by Airtel Uganda for example a reduction from $6 \%$ discount to $4 \%$ discount delays decision on restocking of Airtel Airtime." (R010, Casher)

Order batching: Respondents reported that the delays in restocking of airtel airtime at the distributor company were due to grouping of orders that are mostly preferred by the final consumers and most of the airtime values that were mostly restocked are reported as compared to the delays in restocking of other airtime groups was quoted below

"We frequently restock airtel airtime of lower airtime values of $500 /=$, $1000 /=, 2000 /=$ and $5000 /=$ we usually do the restocking on a weekly basis unlike the delay in airtel airtime of higher values like 10,000 and 20,000 that take more than two weeks to be restocked." (R008, Accountant)

Demand forecast: Respondents reported that the delays in restocking of airtel airtime were due to operational delays when the distributor has to decide on how much quantities of airtime have to be restocked as they anticipate higher demand in future due to changes in seasons as quoted below.

"We face delays in restocking airtel airtime because we expect high demand forecast in future due to changes in seasons." (R002, Casher)

\subsection{Managerial Causes of Delay}

Under managerial causes of delay, behavioral explanations emphasize the bounded reasonableness of decision makers, particularly by failure to account for feedback effects, accumulations, and time delays.

\section{Late arrival of stock}

The causes of delay in restocking of $A A$ were due to late arrival of airtime stock and the DSRs had to go to distribution areas without enough airtime stock due to delays by stock arrival. Therefore this contributed to a delay in restocking of airtel airtime at the distributor company as reflected in the quote below.

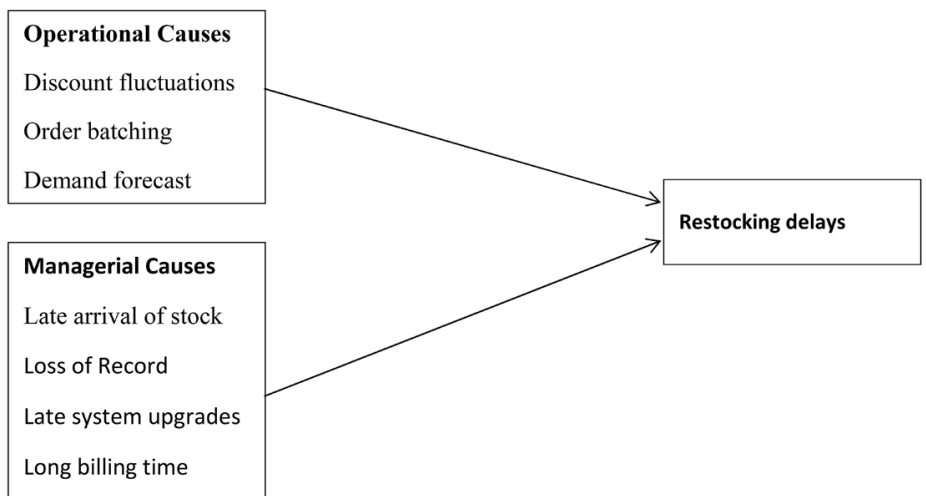

Figure 10. Themes of operational and managerial causes of Restocking Delays. 
"We mostly experience delays due to late arrival of airtime stock at the company and Direct Sales Representatives end up going to the field without some airtime stock which makes us fail to hit our sales targets." (R001, Data Entrant Staff)

\section{Loss of records}

Delays that result from misplacement of records is another cause for delayed restocking of $A A$ at the $D C$ as records are moved from one location to another, records get misplaced and end up getting lost therefore causing delayed access to records as quoted below.

"We face delays when looking for records due to misplacement as records change to hands of different stake holders." (R005, Records Staff)

"We face delays in recovering records that have been corrupted and destroy due to viruses and sometimes we have to retype such records." (R007, Casher)

Late system upgrades

The distributor encountered delays in restocking of airtel airtime when they experience delays in system upgrades in the case of late system upgrades due to the need for upgrading the Microsoft Excel application to capture more records as reflected in the quote below.

"We face delays due to upgrading excel system since it is impossible to retrieve records before it is captured for example this delay takes almost one week in waiting for the system to be upgraded, this delays management to make timely decisions on restocking of airtel airtime." (R012, Accountant Staff)

\section{Long billing time}

The distributor encounters delays in restocking of airtel airtime when a long time is spent as purchased airtime stock for several distributors is billed at airtel Uganda in addition to unavailability of airtel network. 8 out of 12 respondents $(R)$ noted that delays due to long billing time was a cause of restocking delays as this makes the distributor fail to hit the sales targets that they set such as daily, weekly, monthly and annual sales targets as quoted below.

"We usually spend a lot of time at airtel offices for billing purchased stock which has to be verified, approved then cleared for example in March we went to airtel office and network was down and by the time it came it was already late." (R009, Manager)

"We get delays by longer billing time at Airtel Uganda that delays us to meet our weekly sales targets as there is competition from other mobile providers." (R011, Casher)

\section{Conclusive Summary}

It implies that with the developed model for Real Time Inventory Tracking (R.T.I.T) for Airtel Scratch or E-Recharge Airtime in the distribution SC, the line of best fit for Mostly Restocked Airtime is likely to be above a thick line of best fit that represents Messages from Airtel Head Office to the Authorized Dis- 
tributor as in Figure 7.

Delays in arrival of stock when re-stocking, reduced the achievement of weekly sales targets and monthly sales targets. The rate of purchase for lower Denominations of $A A$ was higher as compared to purchase of bigger Denominations of Airtime.

The variables under the stock turnover period construct investigate that the causes for Product Turnover Ratios of $A A$ that negatively affect the Distributor Company $(D C)$ performance of sales were the Delay in Restocking of some of the Airtel products.

\section{Recommendations}

In order to increase the stock turnover periods of the Airtel Scratch or E-Recharge Airtime which are Not Mostly Restocked that shift from Monthly to daily, Weekly or between two weeks interval:

1) There is need to accurately forecast the demand of airtel scratch airtime products called "demand signal processing" to identify areas that increase on the consumption of larger airtime values.

2) The need to implement Real Time models that track Airtel Airtime Inventories so as to check the ordering policy used by retailers called "order batching". Omnichannel Inventory Management (OIM) is a significant contributor to timely reliable inventory restocking

3) There is need for Airtel Uganda to offer attractive and fair discounts rates to the Authorized Distributors that also encourage retailers to buy more of the $A A$ products.

\section{Acknowledgements}

The success in this journal paper has been possible due to the support of my family that is my ultimate role models, and support from the Academic researchers at Busitema University-Faculty of Science and Education especially Dr. Dennis Zami Atibuni, Assoc. Prof. David Olema Kani, Mr. Andrew Oboth, Mr. Andrew Lukyamuzi, Mr. Richard Angole, Assistant Academic Registrar Ms. Chris Achieng and the list continues endlessly for their motivation, encouragement, support and guidance among other contributions towards my career. I am also greatly indebted to Dr. Annabella Habinka Basaza-Ejiri my coauthor, mentor for all the support and to the staff of Airtel Authorized Distributor Company called the Private Marketing and Trading Services (PMTS) Limited whom I had a pleasure to work with in 2017 during the research, while I was pursuing the Masters of Science in Information Systems (MSc.IS) at Mbarara University of Science and Technology (MUST). We thank Almighty God for the generous blessings towards the successful completion of this other paper.

\section{Conflicts of Interest}

The authors declare no conflicts of interest regarding the publication of this paper. 


\section{References}

[1] Modgil, S. and Sharma, S. (2017) Information Systems, Supply Chain Management and Operational Performance: Tri-Linkage-An Exploratory Study on Pharmaceutical Industry of India. Global Business Review, 18, 652-677. https://doi.org/10.1177/0972150917692177

[2] Aiello, L., Dulskaia, I. and Menshikova, M. (2016) Supply Chain Management and the Role of ICT: DART-SCM Perspective. In: Information and Communication Technologies in Organizations and Society, Springer, Berlin, 161-176. https://doi.org/10.1007/978-3-319-28907-6_10

[3] Lee, H.L., Padmanabhan, V. and Whang, S. (2004) Information Distortion in a Supply Chain: The Bullwhip Effect. Management Science, 50, 1875-1886. https://doi.org/10.1287/mnsc.1040.0266

[4] Croson, R., Donohue, K., Katok, E. and Streman, J. (2014) Order Stability in Supply Chains: Coordination Risk and the Role of Coordination Stock. Production and Operations Management, 23, 176-196. https://doi.org/10.1111/j.1937-5956.2012.01422.x

[5] Trujillo, P. (2016) 6 Times Horrific Inventory Control Almost Killed These Companies.

http://www.business2community.com/product-management/6-times-horrific-inven tory-control-almost-killed-companies-01659644\#LyVxkh80qsZpVkVX.99

[6] Musana, E., Okello, W. and Basaza-Ejiri, A.H. (2020) Real Time Inventory Tracking Model in the Distribution Supply Chain of Airtel Airtime. International Journal of New Technology and Research, 6, 46-53. https://doi.org/10.31871/IJNTR.6.7.27

[7] Fang, Z., Gy, B., Luo, X. and Xu, Y. (2015) Contemporaneous and Delayed Sales Impact of Location-Based Mobile Promotions. Information Systems Research, 26, 552-564. https://doi.org/10.1287/isre.2015.0586

[8] Tapiero, C.S. and Grando, A. (2005) Inventory Outsourcing and Risk Management. IFAC Proceedings Volumes, 38, 13-17. https://doi.org/10.3182/20050703-6-CZ-1902.01427

[9] Escudero, L.F., Darin, M.A., Merino, M. and Perez, G. (2016) On Time Stochastic Dominance Induced by Mixed Integer-Linear Recourse in Multistage Stochastic Programs. European Journal of Operational Research, 249, 164-176. https://doi.org/10.1016/j.ejor.2015.03.050

[10] Ataullah, M., Islam, M.E. and Uddin, M.S. (2018) Stochastic Inventory Models with Reworks. Yugoslav Journal of Operations Research, 28, 567-578. https://doi.org/10.2298/YJOR170922027I

[11] Sterling, I. (2020) Three Reasons Why You Need a Better View of Your Inventory. https://www.ibm.com/watson/supply-chain/resources/real-time-inventory-visibility

[12] Subroto, C. (2020) Top 5 Challenges of Real-Time Inventory Visibility. https://fluentcommerce.com/top-5-challenges-of-real-time-inventory-visibility

[13] Joe, S. (2019) Sharpening Omnichannel Inventory Management to a Razor's Edge. https://risnews.com/sharpening-omnichannel-inventory-management-razors-edge

[14] Gruen, T.W. and Corsten, D.S. (2007) A Comprehensive Guide to Retail Out-of-Stock Reduction in the Fast-Moving Consumer Goods Industry.

[15] Devika, K., Jafarian, A., Hassanzadeh, A. and Khodaverrdi, R. (2016) Optimizing of Bullwhip Effect and Net Stock Amplification in Three-Echelon Supply Chains Using Evolutionary Multi-Objective Metaheuristics. Annals of Operations Research, 242, 457-487. https://doi.org/10.1007/s10479-013-1517-y 
[16] Norušis, M.J. (2006) SPSS 14.0 Guide to Data Analysis. Prentice Hall, Upper Saddle River.

[17] Long, J.S. and Freese, J. (2006) Regression Models for Categorical Dependent Variables Using Stata. Stata Press, College Station. 